\title{
Communication
}

\section{First detection and co-occurrence of $k d r$ (F1534C and S989P) mutations in multiple insecticides resistant Aedes aegypti in Nigeria}

\author{
Ifeoluwa Fagbohun ${ }^{1 *}$, Emmanuel Idowu ${ }^{2}$, Tolulope Oyeniyi ${ }^{1}$, Adedapo Adeogun ${ }^{1}$, Kemi Adesalu ${ }^{1}$, Oge \\ Nwanya ${ }^{2}$, Felix Okonkwo², Yusuf Oladosu ${ }^{3}$ and Olubunmi Otubanjo ${ }^{2,}$ \\ 1 Affiliation 1; Molecular Vector Research Laboratory, Nigeria Institute of Medical Research, Yaba, Lagos \\ 2 Affiliation 2; Department of Zoology, University of Lagos. \\ 3 Affiliation 2; Institute of Tropical Agriculture and Food Security, Universiti Putra Malaysia. \\ * Correspondence: fagbohunife@gmail.com
}

Simple Summary: This study described the resistance profile of Aedes aegypti from Lagos State, Nigeria to different classes of insecticides, the presence of knockdown mutations (F1534C, S989P and V1016G) in resistant population of mosquitoes were determined. Results from the study showed that F1534C was presence in resistance population of Aedes aegypti for the first in the Nigeria and S989P for the first time Africa.

\begin{abstract}
The outbreak of yellow fever transmitted by Aedes aegypti has been of major concern in Nigeria, this mosquito also transmits several other arboviruses globally. The control of many of the Aedes aegypti borne diseases relies heavily on the use of insecticides. Therefore, constant monitoring of insecticide resistance status and associated mechanisms in crucial within the local population. Here, we determined the resistance profile of adult Aedes aegypti from Ikorodu Local Government Area of Lagos State, Nigeria to different classes of insecticides using WHO procedures. The presence of $k d r$ mutations F1534C, S989P and V1016G were also determined among resistant populations using molecular methods. High level of resistance to DDT and pyrethroid was recorded in Aedes aegypti in this study, though possible resistance to deltamethrin was reported in one of the locations. Resistance to bendiocarb was recorded in Majidun community while Aedes aegypti in both locations were susceptible to malathion. The presence of F1534C mutation associated with resistance in Aedes aegypti was detected for the first time in Nigeria, and the presence of S989P mutation was detected singly and in co-occurrence with F1534C for the first time in Africa. The role of these mutations in resistance phenotype expressed in Aedes aegypti in this study area need to established.
\end{abstract}

Keywords: Aedes aegypti: Insecticides resistance, kdr mutations, Nigeria.

\section{Introduction}

Aedes aegypti sometimes referred to as yellow fever mosquito is major vector of many parasitic and viral infections of public health importance including lymphatic filariasis, yellow fever, dengue fever, zika virus etc. Diseases transmitted by this mosquito are of growing health concerns in different parts of the world [1,2]. Ae. aegypti are widely distributed around the world, well adapted to urban environments, breeding mainly in containers around peri-domestic areas $[3,4]$. The control of vector-borne diseases on the used or combination of vaccines, chemotherapy or vector control. In the absence of effective vaccines or drugs, control mainly rely on vector management. The use of insecticides-based control tools in vital in regulating the population of both immature and 
adult stage of mosquitoes, including Aedes aegypti. However, resistance to insecticides is being reported in different mosquito species including Aedes aegypti in various parts of the world. In Nigeria, resistance to DDT, pyrethroids and carbamates have been reported in Aedes aegypti from different parts of the country [5-8]. Insecticide resistances in mosquitoes in mainly as a result of the activities of detoxifying enzymes and mutation of the target sites. Detoxification enzymes that have been linked to insecticide resistance include, cytochrome P450 monooxygenases (P450s), carboxylesterases (COEs), and glutathione S-transferases (GSTs). The impact of these detoxifying enzymes in the resistance phenotype expressed by Aedes mosquitoes has been highlighted in some studies in different parts of the world [7-11]. Knockdown resistance $(k d r)$ has been described and associated in DDT and pyrethroid resistance in Aedes [12]. In total, $10 \mathrm{kdr}$ mutations have been reported in Aedes aegypti, varying in frequency, geographical spread and impacts on resistance $[13,14]$. F1534C is the most widely spread $k d r$ mutation in Aedes aegypti and has been reported to confer resistance to deltamethrin and permethrin. The presence of F1534C, V1016I and V410L $k d r$ have been reported across different parts of Africa [11,1416]. V1016G mainly detected in Asia has been reported to cause resistance alone, however more potent when combined with another mutation, S989P. It can lead to extreme resistance when in a triple mutant 989P/1016G/1534C haplotype [13]. Interestingly, S989P/V1016G and F1534C usually occur on alternate chromosomes, but the triple mutant haplotype has been detected in different parts of Asia [13,17]. In Nigeria, a few studies have investigated the resistance profile of Aedes aegypti and the impacts of detoxifying enzymes on the resistant populations but none has provided information on the $k d r$ associated mutations. This study therefore seeks to assess the presence of F1534C, S989P and V1016L among the Nigeria population of Aedes aegypti. 


\section{Materials and Methods}

\section{STUDY LOCATION AND SAMPLE COLLECTION}

This study was conducted in Majidun and Oke-Ota communities of Ikorodu Local Government Area of Lagos State, Nigeria. The study area is situated between $3^{\circ} 27^{\prime} \mathrm{E}-$ $3^{\circ} 28^{\prime} \mathrm{E}$ longitude and $6^{\circ} 37^{\prime} \mathrm{E}$ latitude and covers about $1.71 \mathrm{~km}^{2}$ area of land. Aedes immature stages were collected by using a dippers, sieves and ladles from breeding sites including abandoned tyres, plastic containers, water pots, shallow wells etc. in peri-domestic areas within the surveyed communities. Collections were stored in well labelled plastic containers were transported to the insectary Department of Zoology, University of Lagos, where they were reared under suitable environmental conditions and allowed to emerge to adults.

\section{WHO INSECTICIDE SUSCEPTIBILITY BIOASSAY}

The insecticides susceptibility bioassays were performed on 2-5 days old female mosquitoes using WHO test filter paper impregnated with selected insecticides including Which DDT $(4 \%)$, permethrin $(0.75 \%)$, deltamethrin $(0.05 \%)$, lambdacyhalothrin $(0.05 \%)$, bendiocarb $(0.1 \%)$ and malathion (5\%) using WHO standard procedures [18]. Knockdown was recorded at specific time interval and the 24 hours percentage was also recorded. Mosquitoes' morphological features were assessed using identification keys $[19,20]$.

\section{Screening of $k d r$ mutations in Aedes aegypti}

The detection S989P, V1016G and F1534C mutations in wild Aedes aegypti was done using AS-PCR as described by [21]. The primers for the three targeted mutations are listed in Table 1. The total PCR reaction volume was $12.5 \mu \mathrm{l}$, consisting of $2.5 \mu \mathrm{l}$ of X5 Mastermix, $0.375 \mu \mathrm{l}$ each of primers $(0.3 \mathrm{pmol} / \mu \mathrm{l}), 7.5 \mu \mathrm{l}$ of double-distilled water. PCR conditions were one cycle of $94{ }^{\circ} \mathrm{C}$ for $3 \mathrm{~min}$, then 35 cycles of $94{ }^{\circ} \mathrm{C}$ for $30 \mathrm{~s},\left(54.2^{\circ} \mathrm{C}\right.$ for V1016G and F1534C, and $51.4^{\circ} \mathrm{C}$ for S989P) for $30 \mathrm{~s}$ and $72{ }^{\circ} \mathrm{C}$ for $1 \mathrm{~min}$, followed by one cycle of $72{ }^{\circ} \mathrm{C}$ for $7 \mathrm{~min}$. PCR products were checked by electrophoresis on $1.5 \%$ agarose gel in TBE buffer. Bands were visualized by ethidium bromide staining. The size of the PCR products for the detection of $k d r$ alleles were $348 \mathrm{bp}$ (V1016G), $240 \mathrm{bp}$ (S989P) and $284 \mathrm{bp}$ (F1534C).

Table 1: List of specific primers used to amplify sodium channel gene mutations detected in Aedes aegypti.

\begin{tabular}{|l|l|l|l|}
\hline Mutation & Primers & Sequence $\left(\right.$ 5' $^{\prime}$ '3') & Refereence \\
\hline \multirow{5}{*}{ S989P } & M1-F & AATGATATTAACAAAATTGCGC & [21] \\
\cline { 2 - 3 } & M2-R & GCACGCCTCTAATATTGATGC & \\
\cline { 2 - 3 } & M1-S & GCGGCGAGTGGATCGAAT & \\
\cline { 2 - 3 } & M1-P & GCGGCGAGTGGATCGAAC & \\
\hline V1016G & M2-F & GCCACCGTAGTGATAGGAAATC & \\
\cline { 2 - 3 } & M2-R & CGGGTTAAGTTTCGTTTAGTAGC & \\
\cline { 2 - 3 } & M2-V & GTTTCCCACTCGCACAGGT \\
\cline { 2 - 3 } & M2-G & GTTTCCCACTCGCACAGGG & \\
\hline F1534C & M3-F & GGAGAACTACACGTGGGAGAAC & \\
\cline { 2 - 3 } & M3-R & CGCCACTGAAATTGAGAATAGC & \\
\cline { 2 - 3 } & M3-F & GCGTGAAGAACGACCCGA & \\
\cline { 2 - 3 } & M3-C & GCGTGAAGAACGACCCGC & \\
\hline
\end{tabular}

\section{DATA ANALYSIS.}


Percentage knockdown and percentage mortality to the five insecticides for the mosquitoes from each of the study locations were determined. Insecticide susceptibility of the mosquitoes tested was based on $98-100 \%$ post exposure mortality [18]. Mortality rates $<80 \%$ at 24 hrs post exposure indicated resistance, $>97 \%$ indicated susceptibility and mortality rates between 80 and $97 \%$ indicated that resistance is suspected. The knockdown data was used to compute the $\mathrm{KDT}_{50}$ and KDT90 using log probit analysis. Microsoft Excel version 2016 and IBM SPSS version 23 were for all data analyses.

\section{Results}

The susceptibility status, knockdown time and percentage mortality of Aedes aegypti from Majidun and Oke-Ota communities of Ikorodu LGA is shown in tables 1 and 2 respectively. In Majidun, resistance to DDT, deltamethrin, lambdacyalothrin and bendiocarb with percentage mortality ranging from 33.33 to $76.67 \%$ while susceptibility was recorded to malathion with mortality of $98.83 \%$ (Table 1). Resistance was reported to DDT and lambdacyalothrin in Oke-Ota community with mortality of 62 and $81.14 \%$ respectively, possible resistance was recorded for deltamethrin and susceptibility to malathion and bendiocarb. Figure 1 and figure 2 show the percentage knockdown of Aedes aegypti from Majidun and Oke-Ota communities respectively exposed to different insecticides at various time intervals. After 60minutes of exposure only malathion was able to knockdown all exposed wild Aedes aegypti in Majidun (Figure 1), while malathion and bendiocarb were able to knockdown $100 \%$ wild Aedes aegypti from Oke-Ota community (Figure 2).

The presence of $k d r$ mutations F1534C (Figure 3) and S989P (Figure 4) was detected among DDT and pyrethroid resistance wild population of Aedes aegypti from Ikorodu LGA. The proportion of $k d r$ detected within the resistant population showed F1534C (76\%), S989P (7\%) and co-occurrence of F1534C+S989P (17\%) (Figure 5). None of the Aedes aegypti mosquitoes screened for the presence of V1016G was found carrying this mutation.

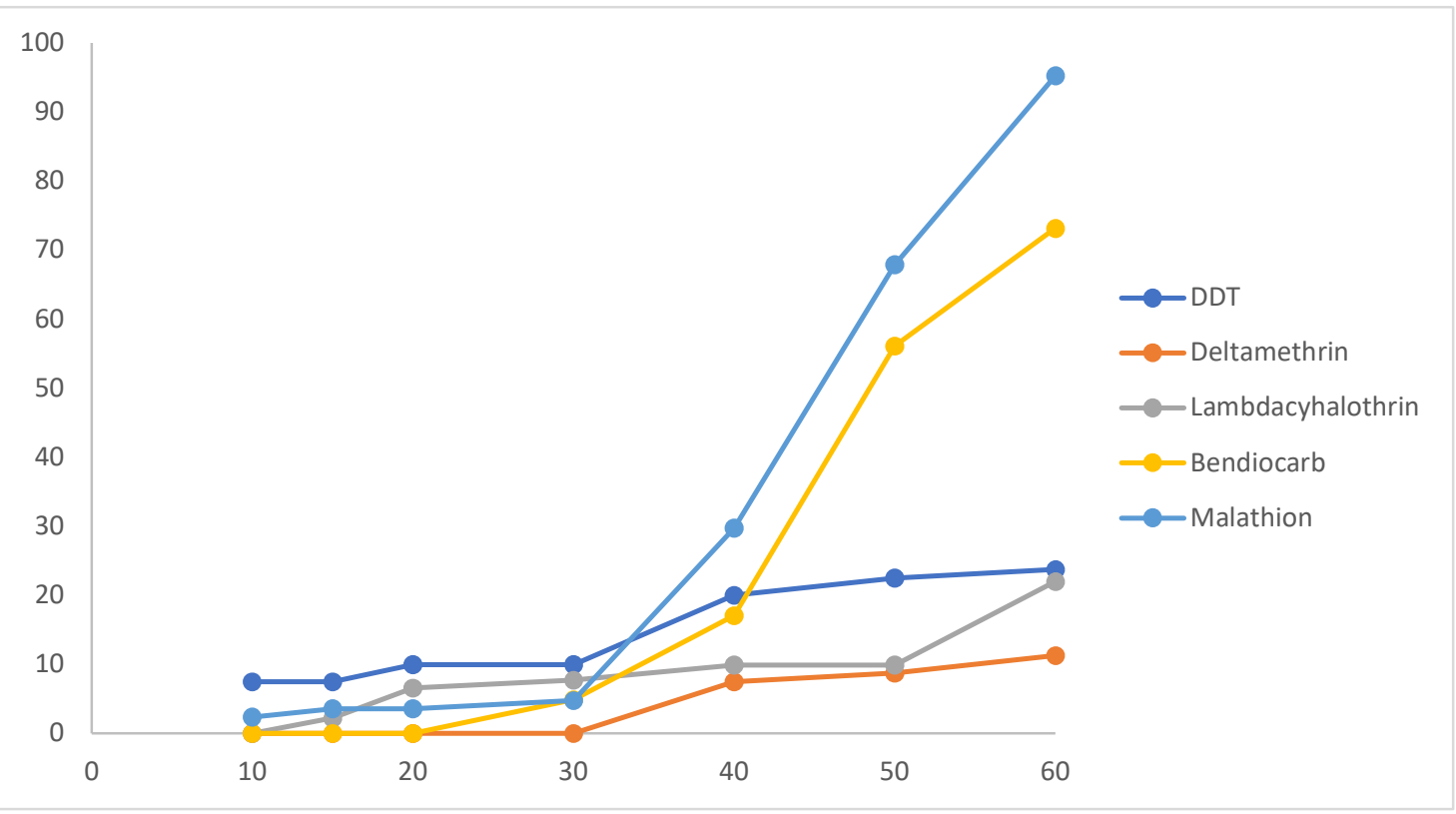


Figure 1: Percentage knockdown at different time intervals of Aedes aegypti from Majidun exposed to different insecticides

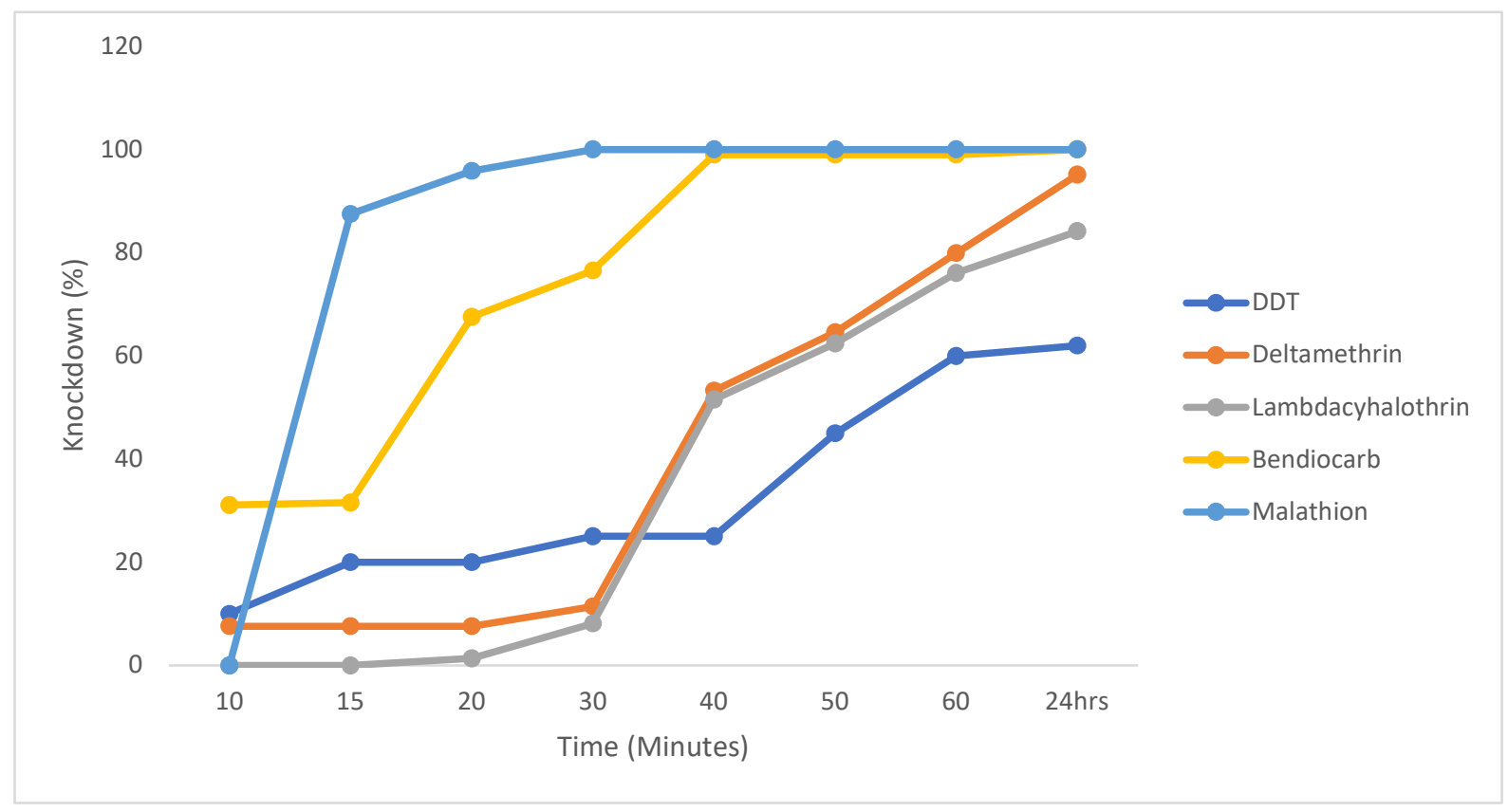

Figure 2: Percentage knockdown at different time intervals of Aedes aegypti from Oke-Ota

exposed to different insecticides

Table 3: Susceptibility status and knockdown time of Aedes aegypti exposed to selected insecticides in Oke-

Ota community, Ikorodu, Lagos State, Nigeria.

\begin{tabular}{|c|c|c|c|c|c|}
\hline Insecticides & $\begin{array}{l}\text { Number } \\
\text { Exposed (N) }\end{array}$ & $\mathrm{KDT}_{50}$ (CI) & $\mathrm{KDT}_{95}(\mathrm{CI})$ & $\begin{array}{l}\text { Mortality } \\
(\%)\end{array}$ & $\begin{array}{l}\text { Resistance } \\
\text { Status }\end{array}$ \\
\hline DDT & 100 & $\begin{array}{l}172.34 \\
(100.27 \pm \\
603.61)\end{array}$ & $\begin{array}{l}4128.32 \\
(970.86 \\
6906.16)\end{array}$ & $\begin{array}{r}62 \\
+\quad\end{array}$ & Resistance \\
\hline Deltamethrin & 97 & $\begin{array}{l}109.76 \\
(82.82 \\
230.66)\end{array} \quad \pm$ & $\begin{array}{l}313.96 \\
(171.29 \\
638.06)\end{array}$ & $\begin{array}{r}95.09 \\
+\quad\end{array}$ & $\begin{array}{l}\text { Suspected } \\
\text { Resistance }\end{array}$ \\
\hline
\end{tabular}




\begin{tabular}{llllll}
\hline Lambdacyhalothrin & 95 & $\begin{array}{l}169.48 \\
(109.57\end{array}$ & $\begin{array}{l}1291.26 \\
(492.88\end{array}$ & 84.14 & Resistance \\
& & $418.90)$ & $1776.02)$ & & \\
Bendiocarb & 99 & $45.64(43.91$ & $66.49(62.19$ & 100 & Susceptible \\
& & $\pm 47.44)$ & $\pm 72.87)$ & & \\
Malathion & 100 & $30.96(27.56$ & $43.37(38.71$ & 100 & Susceptible \\
& & $\pm 38.34)$ & $\pm 45.62)$ & & \\
\hline
\end{tabular}

Table 2: Susceptibility status and knockdown time of Aedes aegypti exposed to selected insecticides in Majidun community, Ikorodu, Lagos State, Nigeria.

\begin{tabular}{|c|c|c|c|c|c|}
\hline Insecticides & $\begin{array}{l}\text { Number } \\
\text { Exposed (N) }\end{array}$ & $\mathrm{KDT}_{50}(\mathrm{CI})$ & $\mathrm{KDT}_{95}(\mathrm{CI})$ & $\begin{array}{l}\text { Mortality } \\
(\%)\end{array}$ & $\begin{array}{l}\text { Resistance } \\
\text { Status } \\
\end{array}$ \\
\hline DDT & 80 & $\begin{array}{l}61.96(42.95 \\
\pm 164.69)\end{array}$ & $\begin{array}{l}598.15 \\
(202.16 \\
2306.52)\end{array}$ & 33.33 & Resistance \\
\hline Deltamethrin & 87 & $\begin{array}{l}39.95(28.98 \\
\pm 67.77)\end{array}$ & $\begin{array}{l}115.26 \\
(67.88 \\
842.51)\end{array}$ & 63.33 & Resistance \\
\hline Lambdacyhalothrin & 91 & $\begin{array}{l}42.95(39.26 \\
\pm 47.06)\end{array}$ & $\begin{array}{l}75.245 \\
(64.63 \\
98.05)\end{array}$ & 43.33 & Resistance \\
\hline Bendiocarb & 82 & $\begin{array}{l}15.90(11.33 \\
\pm 20.03)\end{array}$ & $\begin{array}{l}39.82(29.45 \\
\pm 80.07)\end{array}$ & 76.67 & Resistance \\
\hline Malathion & 84 & $\begin{array}{l}13.32(11.53 \\
\pm 14.89)\end{array}$ & $\begin{array}{l}18.07(15.97 \\
\pm 23.86)\end{array}$ & 98.83 & Susceptible \\
\hline
\end{tabular}

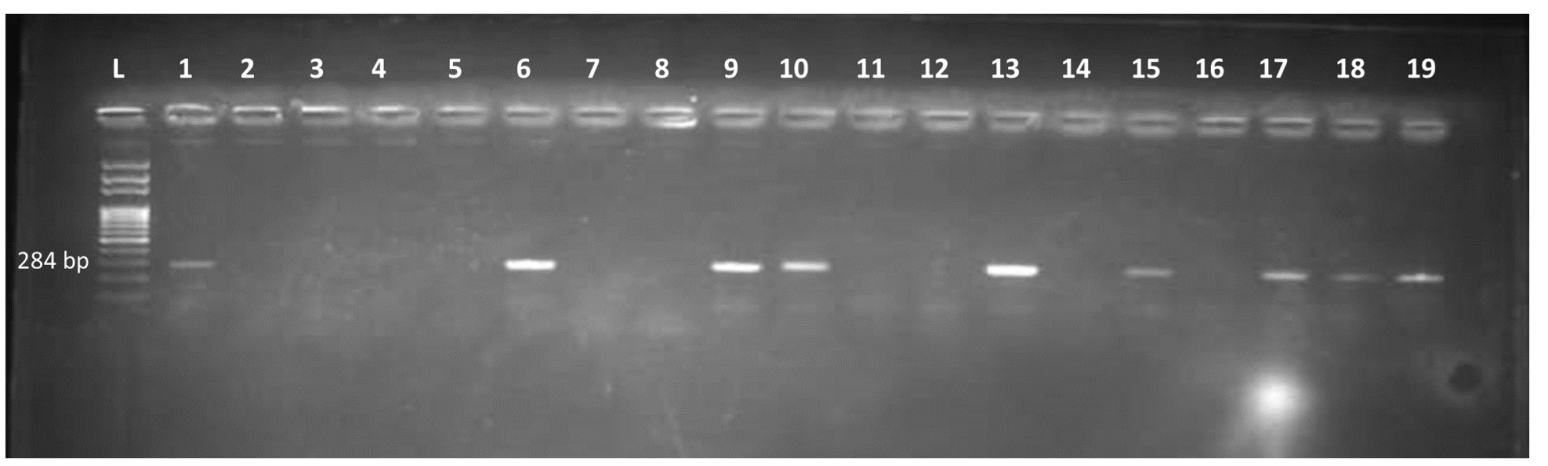

Figure 3: Gel electrophoresis of PCR products screen for sodium channel gene mutations F1534C in Aedes aegypti from Lagos State, Nigeria (L: 100bps DNA ladder). 


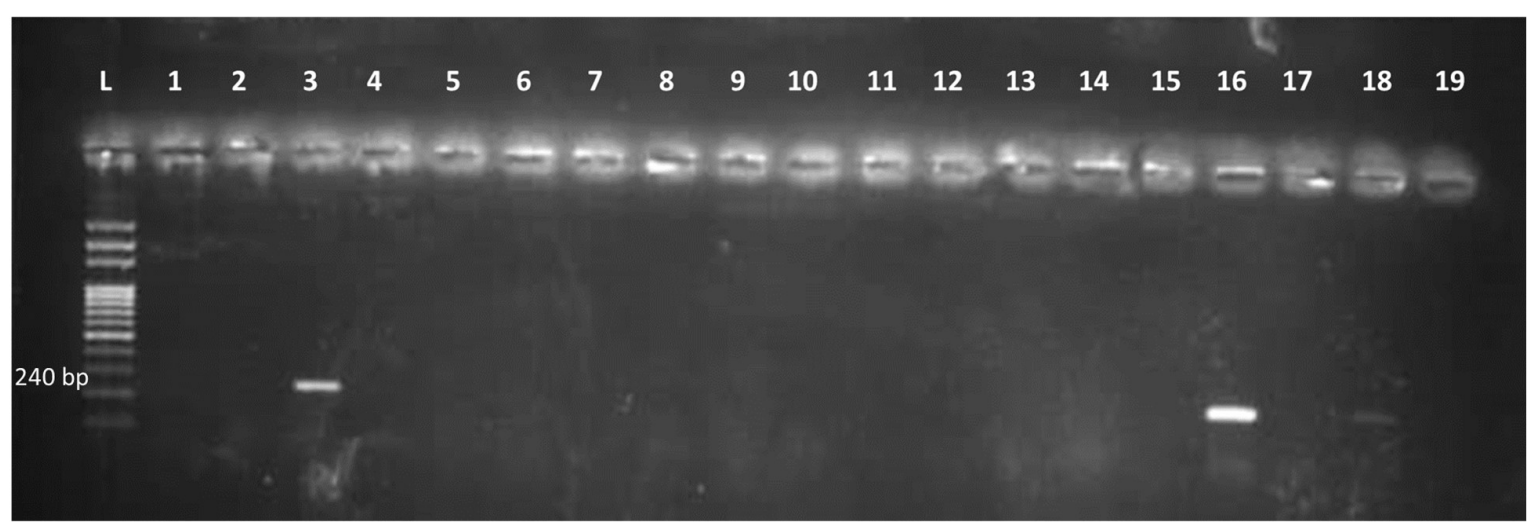

Figure 4: Gel electrophoresis of PCR products screen for sodium channel gene mutations S989P in Aedes aegypti from Lagos State, Nigeria (L: 100bps DNA ladder).

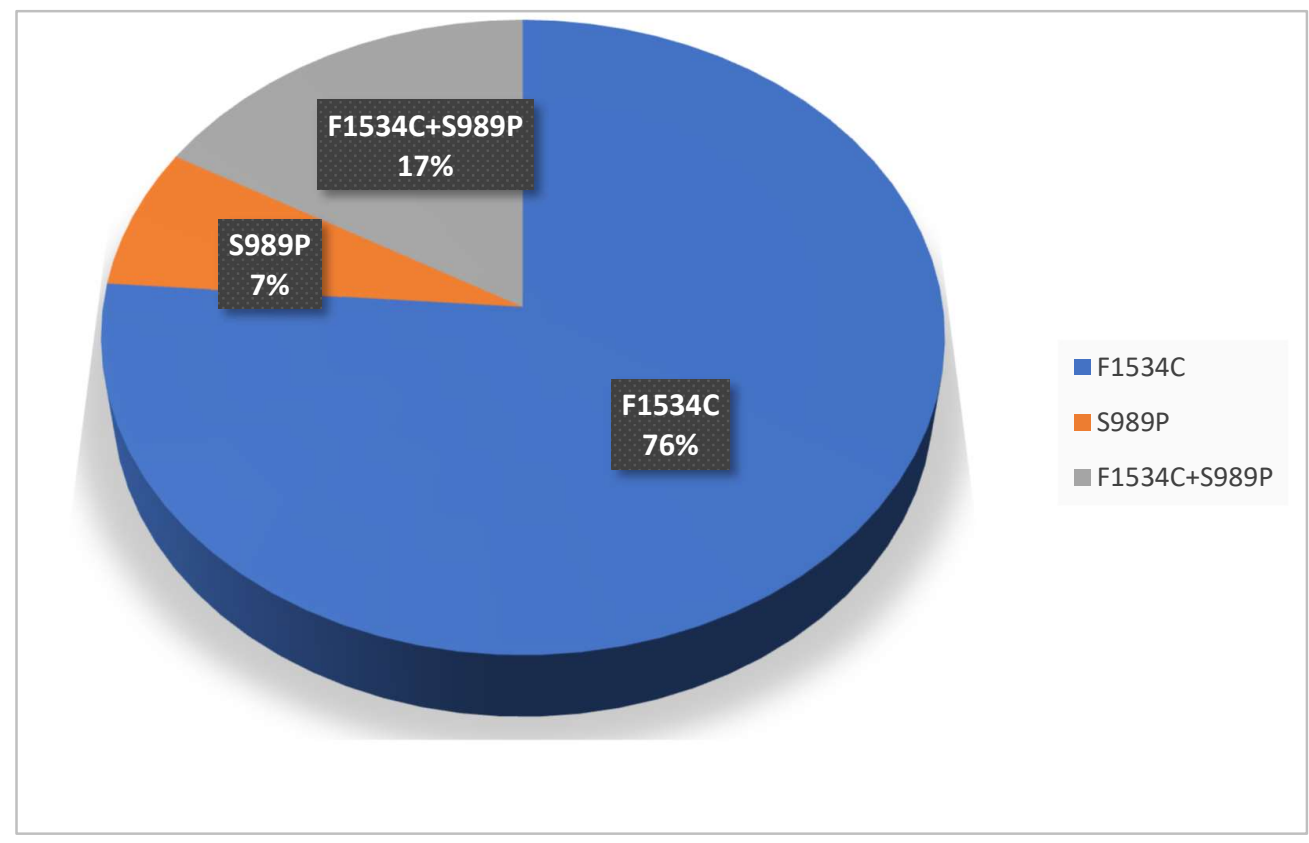

Figure 5: Proportion of sodium channel gene mutation in Aedes aegypti from Lagos State, Nigeria.

\section{Discussion}

This study provides information on the current insecticide resistance status and presence of $k d r$ mutations F1534C and S989P in Aedes aegypti from two communities in Ikorodu LGA of Lagos State, Nigeria.

Results from this study showed resistance to DDT and pyrethroid in the two study communities, similar to previous reports from Lagos State and other parts of southern Nigeria where resistance to DDT has been recorded in Aedes aegypti [6-8]. Resistance to bendiocarb was reported in Majidun community similar to previous report from Kwara State, north-central Nigeria [6] though a similar study in Lagos had reported susceptibility of Aedes aegypti in Lagos State to carbamates [7]. Resistance to the different classes of insecticides recorded in this study maybe as a result of selection pressure from the 
application of pesticides for agricultural purposes and the national scaling up of insecticide-based malaria vector control efforts. Results from this study agrees with previous report in Lagos State where Aedes aegypti were susceptible to malathion [22].

This study also described for the first time the presence of $k d r$ mutation F1534C in Nigeria and S989P in Africa. F1534C have been described to be widely distributed around the world and associated with Aedes resistance to pyrethroid. This mutation has been detected in a couple of African countries [11,14,23]. S989P till now have been described in Asia, it is believed to cause a more potent insecticides resistance when in combination with V1016G or F1534C or both [13]. The co-occurrence of S989P and F1534C was recorded among resistant wild population of Aedes aegypti in the study.

\section{Conclusions}

There is a need for careful monitoring of the occurrence of these and other $k d r$ mutations in Aedes aegypti from Nigeria and Africa at large. There is also need for further studies to validate the association between these mutations and insecticides resistance in Aedes aegypti in these areas and its impact on vector control.

Author Contributions: For research articles with several authors, a short paragraph specifying their individual contributions must be provided. The following statements should be used "Conceptualization, I.F., A.A., E.T., and O.O.; methodology, I.F. T.O., K.A., and Y.O.; formal analysis, I.F., O.N., F.O., and A.A.; investigation, I.F., O.N., F.O., T.O., and K.A. resources, I.F. and Y.O..; data curation, I.F.., O.N., F.O., and T.O..; writing-original draft preparation, I.F. O.N., and F.O..; writing-review and editing, T.O., A.A., E.T., and O.O.; supervision, I.F., E.T., and O.O..; project administration, I.F.; All authors have read and agreed to the published version of the manuscript.

Funding: No finding was received for this study

Institutional Review Board Statement: Not applicable

Acknowledgments: The authors acknowledge the support the staffs of the Molecular Vector Research Laboratory of the Nigeria Institute of Medical Research.

Conflicts of Interest: The authors declare no conflict of interest.

\section{References}

1. WHO Global vector control response 2017-2030; 2017; ISBN 9789241564090.

2. WHO, W.H.O. A global brief on vector-borne diseases; Geneva, 2014;

3. Fagbohun, I.K.; Idowu, E.T.; Awolola, T.S.; Otubanjo, O.A. Seasonal abundance and larval habitats characterization of mosquito species in Lagos State, Nigeria. Sci. African 2020, 10, e00656, doi:10.1016/j.sciaf.2020.e00656.

4. Kamgang, B.; Kusimo, M.O.; Wilson-bahun, T.A.; Irving, H.; Lenga, A.; Wondji, C.S. Geographical distribution of Aedes aegypti and Aedes albopictus ( Diptera : Culicidae ) and genetic diversity of invading population of Ae . albopictus in the Republic of the Congo [ version 1 ; peer review : 2 approved ]. Wellcome Open Res. 2019, 3, 1-13.

5. Ayorinde, A.; Oboh, B.; Oduola, A.; Otubanjo, O.; Zhu, C. The insecticide susceptibility status of aedes aegypti (Diptera: Culicidae) in Farm and Nonfarm Sites of Lagos State, Nigeria. J. Insect Sci. 2015, 15, 2-5, doi:10.1093/jisesa/iev045.

6. Oduola, A.O.; Obembe, A.; Adelaja, O.J.; Ande, A.T. Surveillance and insecticide susceptibility status of Culicine mosquitoes in selected communities utilizing long-lasting insecticidal nets in Kwara State, Nigeria. Anim. Res. Int. 2016, 13, $2483-2491$.

7. Fagbohun, I.K.; Idowu, E.T.; Olakiigbe, A.K.; Oyeniyi, A.T.; Otubanjo, O.A.; Awolola, T.S. Metabolic resistance mechanism in Aedes aegypti from Lagos State, Nigeria. 2020, 8.

8. Adesalu, K.O.; Adeogun, A.O.; Oyeniyi, T.A.; Olakiigbe, A.K.; Jimoh, R.T.; Fagbohun, I.K.; Omotayo, A.I.; Awolola, S.T. Evidence of Metabolic Resistance in Pyrethroid Resistant Aedes aegypti Population from Lagos, Nigeria. Pan African J. Life Sci. 2020, 4, 1-6, doi:10.36108/pajols/0202/40(0330).

9. Ishak, I.H.; Riveron, J.M.; Ibrahim, S.S.; Stott, R.; Longbottom, J.; Irving, H.; Wondji, C.S. The Cytochrome P450 gene CYP6P12 
confers pyrethroid resistance in kdr-free Malaysian populations of the dengue vector Aedes albopictus. Sci. Rep. 2016, 6, doi:10.1038/srep24707.

10. Leong, C.S.; Vythilingam, I.; Wee, J.; Liew, K.; Wong, M.L. Enzymatic and molecular characterization of insecticide resistance mechanisms in field populations of Aedes aegypti from Selangor ,. Parasit. Vectors 2019, 1-17, doi:10.1186/s13071-019-3472-1.

11. Badolo, A.; Sombie, A.; Pignatelli, P.M.; Sanon, A.; Yameogo, F.; Wangrawa, D.W.; Sanon, A.; Kanuka, H.; McCall, P.J.; Weetman, D. Insecticide resistance levels and mechanisms in Aedes aegypti populations in and around Ouagadougou , Burkina Faso. PLoS One 2019, 13, 1-17.

12. Brengues, C.; Hawkes, N.J.; Chandre, F.; Mccarroll, L.; Duchon, S.; Guillet, P.; Manguin, S.; Morgan, J.C.; Hemingway, J. Pyrethroid and DDT cross-resistance in Aedes aegypti is correlated with novel mutations in the voltage-gated sodium channel gene. Med. Vet. Entomol. 2003, 17, 87-94.

13. Moyes, C.L.; Vontas, J.; Martins, A.J.; Ng, L.C.; Koou, S.Y.; Dusfour, I.; Raghavendra, K.; Pinto, J.; Corbel, V.; David, J.P.; et al. Contemporary status of insecticide resistance in the major Aedes vectors of arboviruses infecting humans. PLoS Negl. Trop. Dis. 2017, 11, 1-20, doi:10.1371/journal.pntd.0005625.

14. Sombié, A.; Saiki, E.; Yaméogo, F.; Sakurai, T.; Shirozu, T.; Fukumoto, S.; Sanon, A.; Weetman, D.; McCall, P.J.; Kanuka, H.; et al. High frequencies of F1534C and V1016I kdr mutations and association with pyrethroid resistance in Aedes aegypti from Somgandé (Ouagadougou), Burkina Faso. Trop. Med. Health 2019, 47, 4-11, doi:10.1186/s41182-018-0134-5.

15. Kawada, H.; Y., H.; Futami, K.; Muranami, Y.; Kawashima, E.; Osei, J.H.; Al, E. Discovery of point mutations in the voltagegated sodium channel from African Aedes aegypti populations: potential phylogenetic reasons for gene introgression. PLoS Negl. Trop. Dis. 2016.

16. Ayres, C.F.J.; Seixas, G.; Borrego, S.; Marques, C.; Monteiro, I.; Marques, C.S.; Gouveia, B.; Leal, S.; Troco, A.D.; Fortes, F.; et al. The V410L knockdown resistance mutation occurs in island and continental populations of Aedes aegypti in West and Central Africa. PLoS Negl. Trop. Dis. 2020, 14, 1-12, doi:10.1371/journal.pntd.0008216.

17. Cosme, L.V.; Gloria-Soriaid, A.; Caccone, A.; Powell, J.R.; Martins, A.J. Evolution of kdr haplotypes in worldwide populations of aedes Aegypti: Independent origins of the F1534C kdr mutation. PLoS Negl. Trop. Dis. 2020, 14, 1-18, doi:10.1371/journal.pntd.0008219.

18. WHO Test procedures for insecticide resistance monitoring in malaria vector mosquitoes; 2016;

19. Rueda, L.M. Zootaxa: Pictorial keys for the identification of mosquitoes (Diptera: Culicidae) associated with Dengue Virus Transmission; 2004; ISBN 1877354465.

20. wrbu.org The Walter Reed Biosystematics Unit Available online: http://www.wrbu.org/.

21. Li, C.X.; Kaufman, P.E.; Xue, R. De; Zhao, M.H.; Wang, G.; Yan, T.; Guo, X.X.; Zhang, Y.M.; Dong, Y. De; Xing, D.; et al. Relationship between insecticide resistance and kdr mutations in the dengue vector Aedes aegypti in Southern China. Parasites and Vectors 2015, 8, 1-9, doi:10.1186/s13071-015-0933-z.

22. Fagbohun, K.I.; Idowu, T.E.; Olubunmi, O.A.; Awolola, S.T. Susceptibility status of mosquitoes (Diptera : Culicidae ) to malathion in Lagos, Nigeria. Anim. Res. Int. 2020, 17, 3541-3549.

23. Kawada, H.; Oo, S.Z.M.; Thaung, S.K.E.; Maung, Y.N.M.; Thu, H.M.; Thant, K.Z.; Minakawa, N. Co-occurrence of pointmutations in the voltage-gated sodiumchannel of pyrethroid-resistant Aedes aegypti populations in Myanmar. PLoS Negl. Trop. Dis. 2014, 8. 